Nat. Hazards Earth Syst. Sci., 18, 1771-1783, 2018

https://doi.org/10.5194/nhess-18-1771-2018

(C) Author(s) 2018. This work is distributed under

the Creative Commons Attribution 4.0 License.

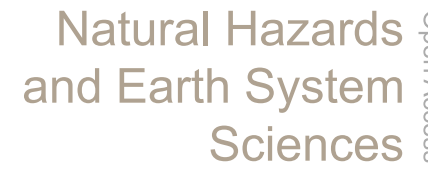

Evu

\title{
Analysis of the disaster characteristics and emergency response of the Jiuzhaigou earthquake
}

\author{
Wei Wang ${ }^{1}$, Hong $\mathrm{Chen}^{2}$, Aihui $\mathrm{Xu}^{2}$, and Minhao $\mathbf{Q u}^{3}$ \\ ${ }^{1}$ Institute of Engineering Mechanics, China Earthquake Administration, Harbin 150080, China \\ ${ }^{2}$ Institute of Crustal Dynamics, China Earthquake Administration, Beijing 100085, China \\ ${ }^{3}$ National Earthquake Response Support Service, Beijing 100049, China
}

Correspondence: Hong Chen (chenhongicd@163.com)

Received: 24 November 2017 - Discussion started: 11 December 2017

Revised: 30 March 2018 - Accepted: 15 June 2018 - Published: 27 June 2018

\begin{abstract}
China's earthquake emergency response system has been improved by lessons learned from multiple earthquakes. This paper focuses on the $M_{\mathrm{s}} 7.0$ earthquake that occurred in Jiuzhaigou County, Sichuan Province, China, on 8 August 2017 and assesses the emergency response activities of all levels of government as well as various departments, rescue teams, enterprises and public institutions and social organizations. The emergency response is compared to other large earthquakes that occurred in China in recent years. The lessons learned from these experiences can inform the emergency response to future disasters. The characteristics of the Jiuzhaigou earthquake and the emergency responses after the event are analysed. The response level and resource mobilization were appropriately adjusted as the disaster developed, and various departments worked together to conduct multi-sector joint rescue efforts. Additionally, professional rescue forces and participating social organizations were more rationally mobilized than during past earthquake emergency responses. A set of effective disaster relief command and coordination mechanisms was established to facilitate cooperation between multiple departments and social organizations under the leadership of the local government. Finally, new and more effective technologies played an important role in the emergency response and rescue efforts following the earthquake.
\end{abstract}

\section{Introduction}

Since the early 1980s, more than 30 laws and regulations on disaster prevention and reduction have been promulgated re- garding earthquakes, meteorological and flood disasters, water pollution, soil desertification, forest fires and environment protection. However, China's modern emergency management was preliminary formed during the SARS (severe acute respiratory syndrome) event in 2003 , which affected as many as 26 provinces and 5327 persons with a death rate of $6.53 \%$ (Li et al., 2004), highlighting the importance of emergency response. China used advanced emergency management concepts of all-hazards approach, integrated emergency management system, emergency life cycle, and emergency planning (Coombs, 1999; Alexander, 2002, 2015; Perry and Lindell, 2003; Greiving et al., 2012) for reference. Since then, China's emergency management system has undergone a significant change, which has led to an integrated response during emergencies. Its approach can be summarized as "one planning plus three systems": emergency response plan, emergency legislation system, emergency institutional system and the emergency regulatory system.

China's emergency response plan has three layers. First is the state overall emergency response plan, the General State Emergency Response Plan for Unexpected Public Emergencies (General Office of the State Council, 2006a) promulgated by the State Council in January 2006. In addition, there are 25 state specialized emergency response plans and 80 departmental emergency response plans (Liu and $\mathrm{Li}, 2010$ ). The state overall emergency response plan divides emergencies into four categories: natural disasters, accidental disasters, public health incidents and social security incidents. Based on the degree of social damage and scope of impact, the response also has four levels: grade I (extremely serious), grade II (serious), grade III (major) and grade IV (ordinary). 
China's emergency response plan system by and large covers the state specialized emergency response plans of all government sectors (the Ministry of Civil Affairs, Ministry of Finance, Ministry of Land and Resources, Ministry of Housing and Urban-Rural Development, Ministry of Transport, National Health and Family Planning Commission, China Earthquake Administration (CEA), etc.) and all government levels (national, provincial, municipal, prefectural and community). Among state specialized emergency response plans, the State Emergency Response Plan for Earthquake applies to emergency response activities such as earthquake disasters (as well as volcanic disasters) (General Office of the State Council, 2012). Based on the Emergency Response Law of the People's Republic of China (The 10th Standing Committee of the National People's Congress, 2007), the Law of the People's Republic of China on Protecting Against and Mitigating of Earthquake Disasters (Standing Committee of the National People's Congress, 2008) and the State Emergency Response Plan for Earthquake, CEA formulated departmental Emergency Response Plan (China Earthquake Administration, 2013). All levels of the government of the People's Republic of China, relevant departments, departments in charge of earthquake-related work, units directly under CEA, key enterprises and institutions, schools, hospitals, communities and condensed populated places have established their own emergency response plans for earthquake. China's emergency response mechanism has continually improved through practical testing during the $M_{\mathrm{S}} 8.0$ Wenchuan earthquake in 2008, the $M_{\mathrm{S}} 7.1$ Yushu earthquake in 2010 and the $M_{\mathrm{s}}$ 7.0 Lushan earthquake in 2013. In the Jiuzhaigou earthquake of 2017, the response activities of various governmental departments at all levels were evaluated as outstanding, and the experience and lessons learned were valuable as China's earthquake emergency response system matures.

\section{Disaster characteristics}

A $\quad M_{\mathrm{S}} 7.0 \quad\left(M_{\mathrm{W}} 6.5\right) \quad$ earthquake struck Jiuzhaigou County, Aba Tibetan and Qiang Autonomous Prefecture, Sichuan Province, China, at 21:19:46 on 8 August 2017 (13:19:46 GMT on 8 August 2017). The epicentre was located at $33.193^{\circ} \mathrm{N}, 103.855^{\circ} \mathrm{E}$ with a focal depth of $20 \mathrm{~km}$. The earthquake occurred along a strike-slip fault at the intersection of the Minjiang, Tazang and Huya faults. The epicentre was $39 \mathrm{~km}$ away from Jiuzhaigou County and $285 \mathrm{~km}$ away from Chengdu, the capital of Sichuan Province. The population density of Jiuzhaigou County is 15 people $\mathrm{km}^{-2}$; however, as August is a popular season for tourism in Jiuzhaigou, there were approximately 40 thousand tourists in the nationally famous Jiuzhaigou scenic areas when the earthquake struck. A total of 25 people were killed in the earthquake (more than half died from rockfalls and landslides), 525 were injured, and 6 were reported missing. In total, 176492 were affected, and 73671 houses were damaged to varying degrees (76 of which collapsed) (Bai, 2017). The earthquake generally had the following disaster characteristics.

1. A low proportion of buildings completely collapsed. The earthquake struck a total of eight counties in Sichuan and Gansu provinces and exhibited a maximum intensity of 9 degrees in the epicentre area. (China uses a 12-degree intensity scale, where 9 degrees indicates that most wood structure house and half-timber structures are either destroyed or seriously damaged; few brick masonry structures are destroyed, though most are either seriously or moderately damaged; and few frame structures are destroyed or most suffer either moderate or minor damage.) The area with an intensity of 9 degrees spanned $139 \mathrm{~km}^{2}$ in Jiuzhaigou County, while the total area with an intensity of 6 degrees exceeded 18295 $\mathrm{km}^{2}$, as shown in Fig. 1 (China Earthquake Administration, 2017). The earthquake region had been previously affected by the Wenchuan earthquake in 2008 , and thus many houses in the disaster area had been rebuilt. These buildings were constructed with a seismic precautionary intensity of 8 degrees, and thus possessed high levels of seismic fortification and favourable shock resistance. Among the damaged houses, only $0.1 \%$ were completely collapsed.

2. Secondary disasters after the earthquake were very serious. The earthquake occurred in a high-elevation mountain gorge, and Jiuzhaigou is situated in the transition zone between the Qinghai Tibet Plateau and the Sichuan Basin, within a valley that is over $50 \mathrm{~km}$ long. The residents and infrastructure are distributed throughout the river valley, and thus residents and vehicles passing adjacent to the high, steep mountains were vulnerable to secondary disasters such as landslides, rockfalls and mudslides. The earthquake triggered at least $622 \mathrm{co}-$ seismic landslides within an image cover $3919 \mathrm{~km}^{2}(\mathrm{Wu}$ et al., 2017), disrupting road traffic, smashing passing vehicles and dislodging large boulders (which were responsible for over half of the 25 victims). The image in Fig. 2 was taken by the author on the day following the disaster. The roads were narrow due to continued landslide activity, and serious rockfalls had occurred. Due to numerous landslides, the natural landscape and environment in the scenic areas of Jiuzhaigou were seriously damaged. Figure 3 shows remote sensing images acquired by UAVs (unmanned aerial vehicles) over the scenic areas in Jiuzhaigou, where the regions delineated with yellow lines represent landslide areas. Figure 4 shows a pair of high-quality satellite remote sensing images of Huanglong Airport, near the epicentre, before and after the earthquake. In total, six landslides were triggered by the earthquake, causing severe traffic disruptions. 


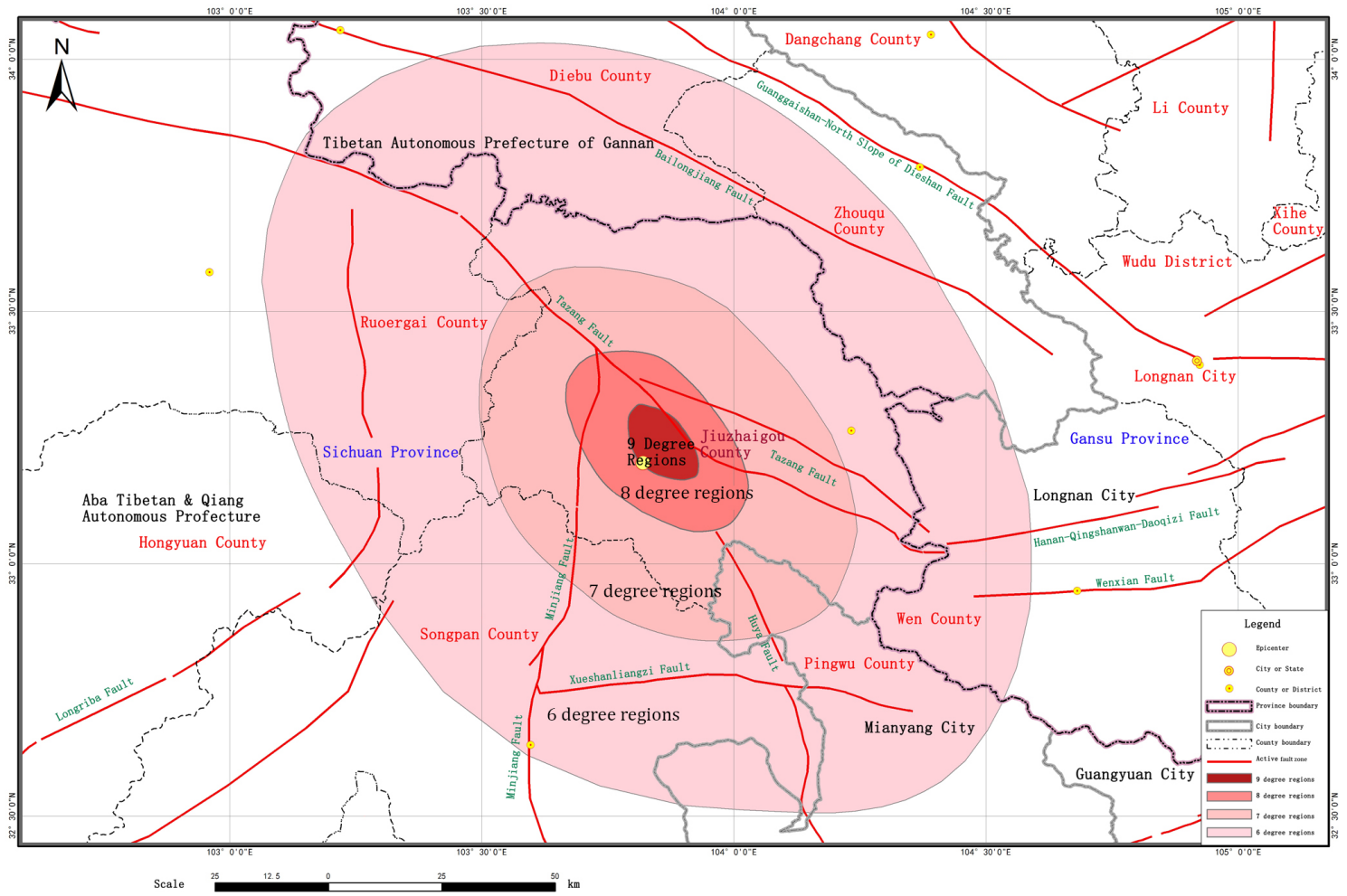

Figure 1. Seismic intensity map of the $M_{\mathrm{S}} 7.0$ earthquake that occurred in Jiuzhaigou County, Sichuan Province.

3. There were disruptions to infrastructure, including electricity, communication and traffic systems. Jiuzhaigou County had power failures and mobile phone signal interruptions after the earthquake. In addition, 234 base stations (accounting for $43 \%$ of the total number) were out of service. In total, $2910 \mathrm{kV}$ power lines were suspended after the earthquake, resulting in power outages to more than 1900 households. Power was restored to Jiuzhaigou County and the scenic areas within $2 \mathrm{~h}$ after the earthquake. Electricity service was basically restored within the $48 \mathrm{~h}$ following the earthquake. National highway G213 and provincial highway S301 were blocked in many places due to hillslope collapse and rockfalls. These roads were fully accessible $20 \mathrm{~h}$ after the earthquake.

\section{Emergency response}

The features of China's earthquake emergency response command and control system are central leadership, departmental responsibility, disaster administration at different levels and major responsibility of local government. Under the unified leadership of the State Council, the central organ organizing and coordinating earthquake disaster response work is the State Earthquake Control and Rescue Headquarters (SECRH), whose office is set up in the CEA and

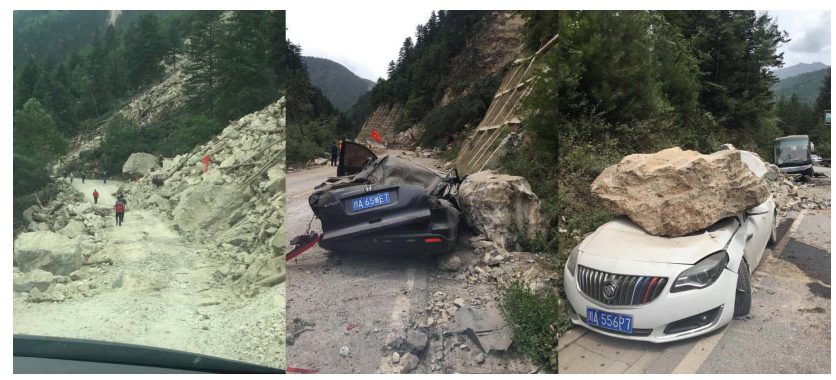

Figure 2. Landslides and rockfalls in the disaster area.

contains other relevant ministries and commissions. Provincial, municipal and prefectural earthquake control and rescue headquarters (ECRH) are similarly constituted in accordance with requirements. When the earthquake occurs, different responses will be set in motion depending on the different earthquake disaster level, as shown in Fig. 5.

Grade I emergency response measures should be started when dealing with extremely serious earthquake disasters, and emergency and response operations in the disaster area should be led by the provincial ECRH, while the SECRH should be responsible for unified leadership, command and coordination of the earthquake response operations nationwide. Grade II emergency response measures should be started when dealing with serious earthquake disasters, and 


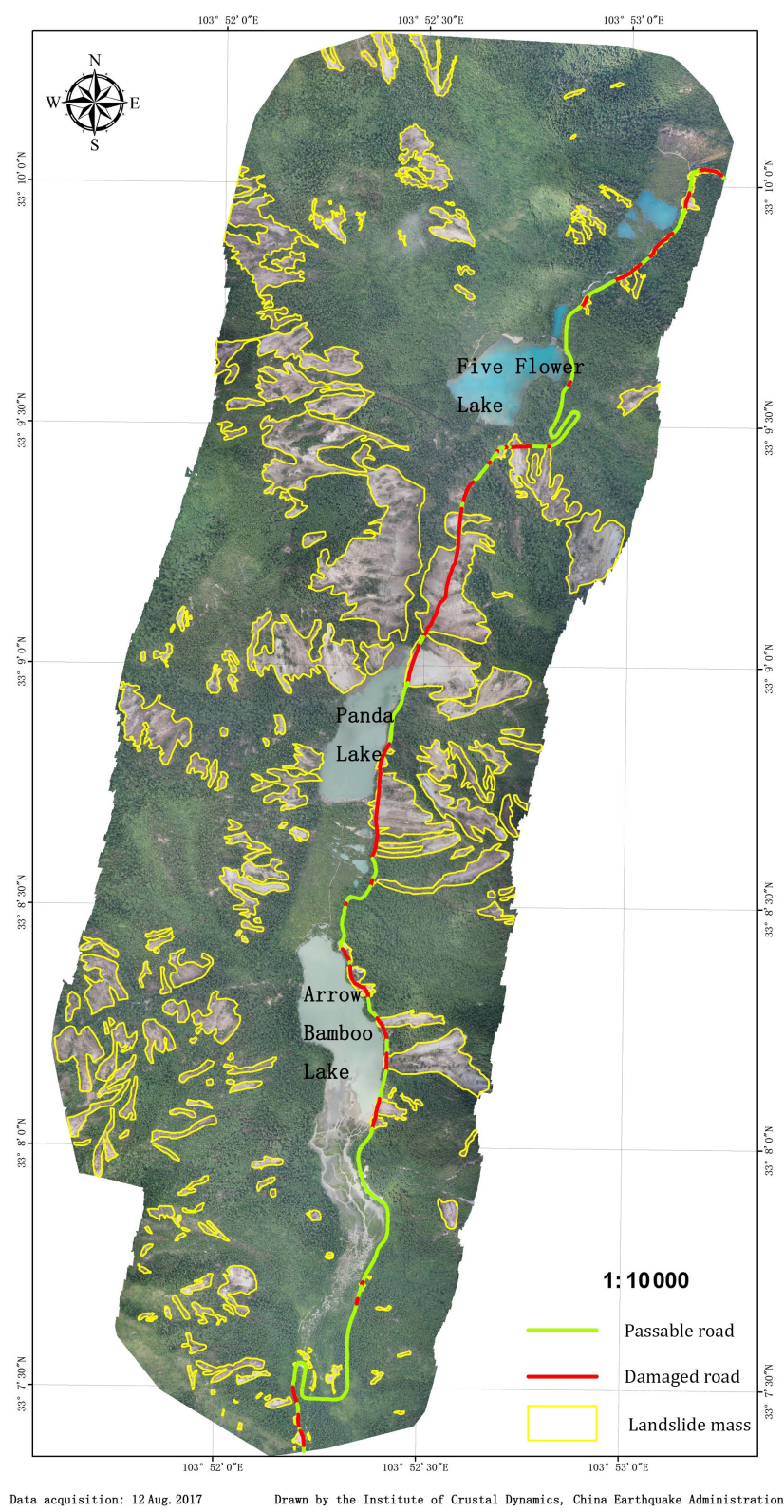

Figure 3. Post-seismic remote sensing images acquired by a UAV in the Jiuzhaigou scenic area.

emergency and response operations in the disaster area should be led by the provincial ECRH, while the SECRH should organize and coordinate the relevant departments and units to conduct emergency efforts at the national level in accordance with the disaster conditions. Grade III emergency response measures should be started when dealing with major earthquake disasters and, with the support of the provincial ECRH, emergency and response operations in the disaster area should be led by the municipal ECRH, while the CEA and relevant departments and units will offer assistance in accordance with requirements. Grade IV emergency response measures should be started when dealing with ordi-

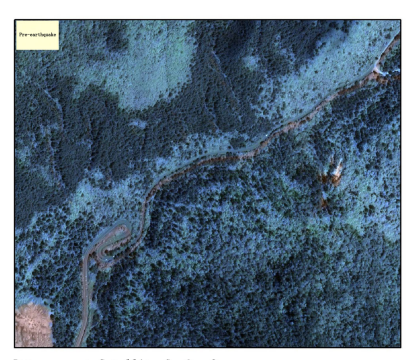

Data acquisition: 9 Aug. 2017
Data source: Satellite Gaofen-2

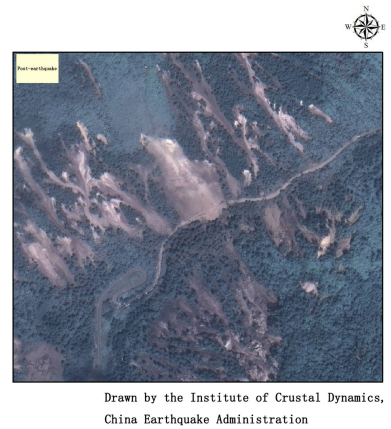

China Earthquake Administration
Figure 4. Comparison of remote sensing images surveying the road damage before and after the earthquake along the No. 301 provincial highway, Jiuzhaigou County, Sichuan Province.

nary earthquake disasters and, with the support of the provincial and municipal ECRH, emergency and response operations in disaster area should be led by the prefectural ECRH, while the CEA and relevant departments and units will offer assistance in accordance with requirements.

\subsection{Emergency response of major governmental departments}

When the earthquake occurred, the central government quickly initiated its emergency response mechanisms. Based on the State Emergency Response Plan for Earthquake, SE$\mathrm{CRH}$ decided to launch grade II emergency response and sent a joint working group by major governmental departments to the disaster area to guide and coordinate rescue operations; provincial ECRH was in charge of the work. Major governmental departments launched emergency responses rapidly and conducted information sharing and multi-sector joint rescue efforts that provided scientific insights and contributed to efficient earthquake relief (Table 1).

\subsection{Emergency response of the local government}

Sichuan Province and Aba Prefecture both launched earthquake emergency responses based on their earthquake emergency response plans (General Office of the Sichuan Provincial Government, 2012; General Office of the Aba Prefectural Government, 2012). Local government established three organizations to support the emergency response.

First, based on the state emergency response level, the Sichuan provincial government established a provincial ECRH called the $8.8 \mathrm{ECRH}$; this included a medical support group, traffic management support group, communication and power support group, relief material group and publicizing and reporting group. The 8.8 ECRH deployed five missions following its first conference at 06:00 on $9 \mathrm{Au}-$ gust 2017 ( $9 \mathrm{~h}$ after the earthquake): search and rescue, providing emergency rehabilitation to power, communication and roads, relocating victims and evacuating visitors, monitoring secondary disasters, publishing disaster relief infor- 
Table 1. Emergency responses of major governmental departments.

\begin{tabular}{|c|c|}
\hline Departments & Specific aspects of emergency response work \\
\hline $\begin{array}{l}\text { State } \\
\text { Earthquake } \\
\text { Control and } \\
\text { Rescue } \\
\text { Headquarters, } \\
\text { China } \\
\text { Earthquake } \\
\text { Administration }\end{array}$ & $\begin{array}{l}\text { Launched a grade I emergency response } 1 \mathrm{~h} \text { after the earthquake, which was adjusted to a grade II emergency } \\
\text { response according to the disaster situation } 3 \mathrm{~h} \text { after the earthquake. } \\
\text { Dispatched an emergency site team to assess and evaluate the disaster characteristics, monitor aftershocks, } \\
\text { analyse trends in seismic data, assess earthquake intensity and investigate and evaluate the disaster area. } \\
\text { Dispatched CISAR to the disaster area. } \\
\text { Research institutes under the CEA carried out a series of studies on the occurrence, faults, focal mechanism } \\
\text { and seismic intensity of the earthquake to provide technical support for earthquake relief efforts. } \\
\text { Terminated the emergency response } 11 \text { days after the earthquake. }\end{array}$ \\
\hline $\begin{array}{l}\text { China National } \\
\text { Committee for } \\
\text { Disaster } \\
\text { Reduction, } \\
\text { Ministry of } \\
\text { Civil } \\
\text { Affairs, } \\
\text { Ministry of } \\
\text { Finance }\end{array}$ & $\begin{array}{l}\text { Launched a grade III state disaster relief emergency response launched (General Office of the State Council, } \\
\text { 2016). } \\
\text { Local Department of Civil Affairs immediately established a working group in the disaster area to assess the } \\
\text { needs of the relief efforts, raise and transport relief supplies, coordinate social organizations and volunteer } \\
\text { teams, receive donations and supervise relief funds and materials. } \\
\text { Fourteen hours after the earthquake, the Ministry of Finance and the Ministry of Civil Affairs allocated a total } \\
\text { of CNY } 100 \text { million from the central government's Natural Disaster Subsistence Allowance to guarantee the } \\
\text { victims' basic livelihood. }\end{array}$ \\
\hline
\end{tabular}

\begin{tabular}{ll}
\hline National & Secure electricity supply, food supply and price stability in the disaster area. \\
Development & Two hours after the earthquake, restored power in Jiuzhaigou County and surrounding scenic areas. \\
and Reform & Petrol stations opened green channel to provide priority for earthquake relief vehicles. \\
Commission & $\begin{array}{l}\text { On 9 August 2017, CNY } 60 \text { million (a disaster relief emergency subsidy from the Central Budget Investment) } \\
\text { were allocated for the reconstruction of infrastructure and public welfare facilities. }\end{array}$
\end{tabular}

Ministry of Launched a grade II emergency response (Ministry of Transport of the People's Republic of China, 2009),

Transport deployed emergency personnel from the Department of Transportation of Sichuan Province to unblock roads connecting the airport with earthquake region so that rescue persons and supplies could be delivered. Monitored and controlled the key roads via satellite communications and other technological means. The Civil Aviation Administration of the Ministry of Transport immediately launched a response to ensure that passenger evacuations, rescue crews and supplies for transport were conducted in a timely manner. As of 17:30 on 9 August 2017 ( $20 \mathrm{~h}$ after the earthquake), they opened all national and provincial highway in the disaster area. More than 40000 stranded passengers were evacuated; of these, nearly 9000 tourists were safely evacuated by emergency vehicles.

Ministry of Industry and Information Technology
Deployed communications authorities and communications enterprises in the disaster area to provide emergency communications support, keep satellite telephone communications unblocked and support scheduling and command efforts for first-line rescue teams.

Four hours after the earthquake, they restored communications to Jiuzhaigou Entrance.

China Mobile, China Unicom and China Telecom immediately launched a tracing hotline to provide satellite communications for disaster relief. In addition, free service points were set up in the earthquake areas to provide on-site consultations, free charging and telephones to receive safety and disaster-warning messages.

Thirty-nine hours after the earthquake, a total of 127 base stations had recovered (54\% of the total number of damaged base stations in Jiuzhaigou County).

Fifty hours after the earthquake, communications resumed normally in the disaster area, and the reconstruction of communications systems officially began on 16 August 2017. 
Table 1. Continued.

\begin{tabular}{ll}
\hline Departments & Specific aspects of emergency response work \\
\hline $\begin{array}{l}\text { National Health } \\
\text { and Family }\end{array}$ & $\begin{array}{l}\text { Personnel were immediately deployed to understand the disaster situation, guide localities in conducting rescue } \\
\text { operations, provide medical services, arrange national health and medical emergency teams, prevent epidemics }\end{array}$ \\
Commission & and provide psychological experts in the regions surrounding the disaster area. \\
& $\begin{array}{l}\text { The West China Hospital of Sichuan University sent } 8 \text { experts, } 2 \text { ambulances and supplies to the disaster area } \\
\text { in Jiuzhaigou } 2.5 \mathrm{~h} \text { after the earthquake. }\end{array}$ \\
& $\begin{array}{l}\text { The hospitals in nearby cities and counties were organized to receive and treat the wounded immediately after } \\
\text { the earthquake. In addition, medical teams were dispatched to the disaster area to perform triage and treat the } \\
\text { injured. More than } 10 \text { medical teams and nearly } 500 \text { medical personnel were deployed to treat the wounded } \\
\text { and prevent diseases after the earthquake. }\end{array}$ \\
\hline
\end{tabular}

Ministry of Launched a grade I geologic hazard emergency response launched (General Office of the State Council, Land and 2006b), after which provincial, municipal and prefectural working teams were established. Twelve units, 237 Resources specialists and professors and 164 technicians were sent to the disaster area to evaluate the landslides and other geological secondary disasters and assess the safeties of temporary shelters. Safety assessments of potential geological hazards were conducted for 339 temporary victim shelters to guide the secure selection of sites and ensure the safety of the masses.

Potential geological hazards in the post-earthquake disaster area were examined, and 1258 various potential geological hazards were investigated and verified. In addition, remote sensing and other monitoring technologies were used to assess potential geological hazards to support the safety of rescue and relief efforts.
Ministry of Verified the earthquake casualties and confirmed the damage estimates for rural houses, municipal infrastruc- Housing and tures and scenic areas. Large rescue machinery and equipment and specialists from major industries were Urban-Rural transferred and assembled for rescue and relief teams and emergency evaluation teams and to evaluate emer- Development gency losses and emergency restoration efforts for urban and countryside housing and public utilities in the disaster area.
The gas pipeline network throughout the disaster area was examined and repaired to ensure the security and timeliness of the fuel supply.
The post-disaster reconstruction stage began on 18 August. A total of 305 temporary shelters were established for more than 27000 people.

\begin{tabular}{ll}
\hline $\begin{array}{l}\text { State } \\
\text { Administration } \\
\text { of Quality } \\
\text { and Technical } \\
\text { Supervision }\end{array}$ & $\begin{array}{l}\text { A 96-person rescue team consisting of the Sichuan Province Safety Supervision Bureau and the Sichuan Coal } \\
\text { Supervision Bureau was deployed with search and rescue equipment to the disaster area for rescue operations. } \\
\text { Eight hours after the earthquake, the rescue team had arrived at the field headquarters and begun the rescue } \\
\text { mission. }\end{array}$ \\
$\begin{array}{l}\text { In total, more than } 600 \text { personnel from } 12 \text { mine emergency rescue teams, } 2 \text { hazardous chemical emergency res- } \\
\text { cue teams of Sichuan Province, more than } 400 \text { personnel from } 4 \text { mine rescue teams and } 2 \text { hazardous chemical } \\
\text { emergency rescue teams from Chongqing awaited orders to reinforce the Sichuan earthquake relief efforts. }\end{array}$ \\
\hline $\begin{array}{l}\text { China } \\
\text { Meteorological } \\
\text { Administration }\end{array}$ & $\begin{array}{l}\text { Administration, 2010), and the National Meteorological Centre and Sichuan Province Observatory held a video } \\
\text { conference for consultation. Close attention was paid to the latest dynamic weather conditions in the disaster } \\
\text { area and possibly affected surrounding areas, and meteorological support service was provided for the earth- } \\
\text { quake relief efforts. } \\
\text { One hour after the earthquake, the first earthquake disaster relief weather forecast was transmitted from the } \\
\text { Jiuzhaigou County Weather Bureau. }\end{array}$
\end{tabular}

Ministry of Notice was immediately provided to units in the disaster area to identify and mitigate potential risks in earthWater Resources quake region, monitor changes in the atmosphere including rain conditions, water regime and torrential mountain disasters, examine the damage to reservoir dams at the epicentre and surrounding regions and conduct preparatory efforts for rescue and relief.

The Sichuan Province Hydrographic Office immediately established an emergency rush repair headquarters to monitor hydrological emergencies, analyse changes in the rivers, determine whether quake lakes had formed and provide timely and accurate hydrological information for earthquake relief work.

On the third day after the earthquake, security checks were repeated for the major reservoir dams near the disaster area, and technical support was provided for emergency disposal. The Water Conservancy Department of disaster area organized specialists to conduct on-site surveys in the Jiuzhaigou scenic areas to discuss the causes of damage and potential solutions and to provide hydraulic engineering for the restructuring of the scenic areas. 


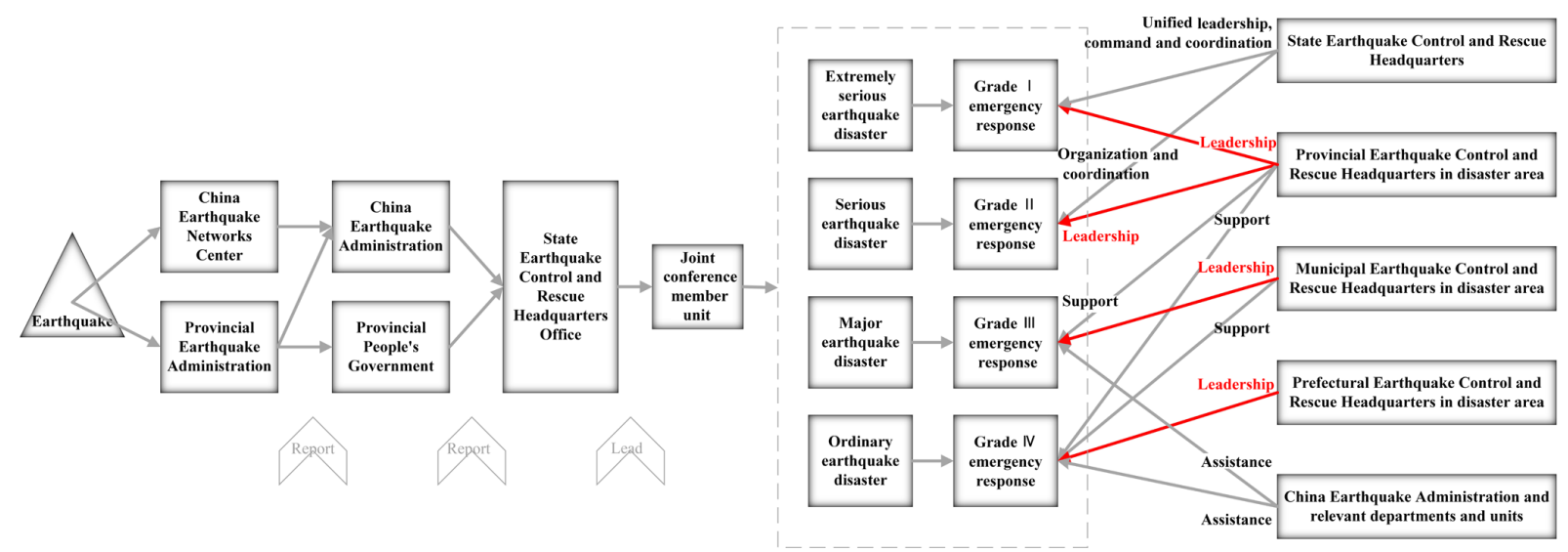

Figure 5. China's earthquake emergency response command and control system.

mation in a timely manner and maintaining social stability. In addition, the $8.8 \mathrm{ECRH}$ convened its first press conference only $2 \mathrm{~h}$ after the earthquake, at which it announced the earthquake situation, casualties and the progress of rescue and relief efforts to the public.

Second, Jiuzhaigou County government established a working station for an 8.8 Earthquake Relief Social Organization and Volunteer Service Centre, or $8.8 \mathrm{SC}$ for short. This entity uniformly managed and deployed social rescue forces to ensure that social organizations and volunteer teams could participate in rescue operations methodically and effectively based on experience from the Wenchuan earthquake.

Third, Sichuan Province established an 8.8 Jiuzhaigou Earthquake Post-Disaster Reconversion Committee on 28 August 2017, to formulate plans for reestablishment, environmental modification, geological disaster prevention and control, scenic area recovery, industrial development, reestablishment of infrastructure and public service, and reconstruction of urban and rural housing.

All of the local government entities at the provincial, municipal and prefectural levels immediately launched earthquake emergency responses and deployed emergency rescue teams following their superior central departments. Within $14 \mathrm{~h}$ after the earthquake, 505 medical technicians and 130 ambulances had been dispatched to counties in the disaster area. Consequently, a total of 217 wounded were treated, 166 people received ambulatory treatment, and 51 people were hospitalized. The Traffic Police Divisions of Sichuan and Gansu provinces dispatched more than 1700 personnel and 5325 vehicles to control traffic, and more than 30000 people were evacuated. The Sichuan Department of Civil Affairs allocated and transported a total of 3000 cotton quilts, 3000 units of cotton clothing, 2000 tents, 1000 folding beds, 3000 sleeping bags and 50 emergency lighting power generation assemblies to the disaster area (Department of Civil Affairs of Sichuan Province, 2017).

\subsection{Emergency response of governmental rescue teams}

Only local armed police, fire forces, the Western Theater Command of the People's Liberation Army and the China International Search and Rescue team (CISAR) were dispatched.

When the earthquake occurred, the Western Theater Command dispatched land and air forces to conduct search and rescue missions. Within $21 \mathrm{~h}$ after the earthquake, a total of 1285 soldiers, 90 vehicles of various types, 9 airplanes and $2.4 \mathrm{t}$ goods and materials were dispatched to the disaster area (Y. Wang, 2017). By 10 August, a total of 143 collapsed building had been cleared, 144 trapped victims had been rescued and more than 100 wounded had been transferred.

Local armed police forces in the disaster area rapidly organized the evacuation of on-site people. At 16:00 on 9 August 2017 (19h after the earthquake), the armed police had dispatched a total of 1958 soldiers and 105 units of equipment and machinery to conduct emergency rescue missions and evacuated a total of 6000 people, transferred 100 wounded, established 10 tents and excavated the remains of 1 victim (Qian, 2017).

By 00:30 on 9 August ( $3 \mathrm{~h}$ after the earthquake), the main Public Security Fire Corps of Sichuan Province had dispatched all 21 detachments of the entire province to the field, including 1108 soldiers, 396 vehicles, 55 life detection instruments, 30 search and rescue dogs, 33 sets of floodlights and 24 electric generators. By 10 August, a total of 9 trapped victims had been rescued and more than 4300 people had been transferred; 21 troop crawlers and passenger buses transferred more than 1200 stranded travellers and employees in the Jiuzhaigou scenic areas.

The CISAR team included 80 personnel, carrying 5 search and rescue dogs, 2 rescue equipment vehicles and a total of 378 units of rescue equipment, including 8 types of life detection instruments, shoring equipment and break-in tools. The team arrived in the disaster area at 19:25 on $9 \mathrm{Au}-$ gust ( $22 \mathrm{~h}$ after the earthquake) and divided into four squads 
to search for missing people in four villages, assess the safety of structures, provide medical attention and assist in transferring goods and materials. In addition, the remains of a victim were transferred on the afternoon of 12 August (CISAR, 2017).

\subsection{Emergency response of enterprises and public institutions}

Enterprises and public institutions also launched their emergency response plans immediately following the earthquake. At 09:00 on 9 August (12 h after the earthquake), a total of 30 enterprises and public institutions had participated in the rescue and relief efforts by dispatching rescue forces to the front lines (L. Wang, 2017). Various power, communication, aviation, tourism, oil play, construction, traffic and railway enterprises joined the response and rescue efforts.

The power enterprises restored electric power in $\mathrm{Ji}$ uzhaigou County and the scenic areas within $2 \mathrm{~h}$. The communication enterprise immediately opened a hotline for people seeking lost relatives and rushed to address emergency rescue workers. The aviation enterprise safeguarded the transport of rescuers, goods and materials. The tourism enterprise reached out to tourists one by one and ensured the safety of both Chinese and foreign tourists. The oil industries opened a green channel and made ready for provisions. Construction, traffic and railway enterprises checked roads and tunnels to ensure that they were unobstructed and dispatched their emergency squads on search and rescue missions. Many other enterprises rapidly assembled personnel and supplies for field rescue efforts; for instance, the Sinopharm Group launched their special storage allocation emergency response plan and secured an adequate supply of blood products and other drugs required in the disaster rescue efforts. Incomplete statistics suggest that at least 33 insurance companies provided emergency measures by providing all-day, full-time services for rapid settlement of insurance claims in the disaster area.

\subsection{Emergency response of social organizations}

The Red Cross Society of China, the Sichuan Red Cross Society and the Chinese Red Cross Foundation all launched emergency responses when the earthquake occurred. They quickly allocated relief goods and emergency funds in support of the emergency rescue efforts.

Less than $2 \mathrm{~h}$ after the earthquake, the first social organization rescue team had already arrived in the disaster area and immediately began rescue efforts. As of 12 August, a total of 219 social organizations and more than 2288 volunteers had registered at the $8.8 \mathrm{SC}$ (Gao, 2017). Social organization rescue operations acted in accordance with the unified arrangement of the 8.8 SC and, consequently, they entered and evacuated the disaster area on time. Social organization rescue teams identified hidden dangers, transferred disaster-affected people, assisted with the evacuation of visitors and provided orderly maintenance and psychological counselling for stranded visitors in temporary shelters. The 8.8 SC coordinated the efforts of all involved parties, constructed volunteer service sites near vital communications lines, stations, hospitals and other crucial locations, and dispatched more than 1200 volunteers to provide volunteer service in the towns, including transporting and distributing relief materials, guiding traffic, providing psychological comfort, relocating stranded visitors and caring for the wounded (China Volunteer Service Federation, 2017).

Among these teams, the Blue Sky Rescue Team sent a total of 12 teams and 259 team members, performed search and rescue operations, evacuated people, constructed tents, offered medical assistance, verified information, distributed relief materials, transferred victims and generated disaster situation assessment reports. They successfully discovered 10 victims and the remains of 5 others who had been trapped in the scenic areas without communication for more than $40 \mathrm{~h}$. All the teams in the Blue Sky Rescue Team evacuated from Jiuzhaigou before 20:00 on 12 August according to the 8.8 ECRH. Helicopter rescue forces also participated in the Jiuzhaigou earthquake rescue operations. Due to physical restrictions on land-sky military helicopters, the SECRH dispatched two Airbus helicopters from Xilin Fengteng General Aviation Co. Ltd. to the dead zone of the earthquake disaster area to conduct search and rescue operations for trapped, sick and wounded people, during which a total of 30 victims were saved.

\subsection{Comparison of the emergency response to four large earthquakes}

Table 2 compares of the disaster situation (Zheng et al., 2010, 2011; Chen et al., 2014; Zheng and Zheng, 2015) and emergency response data (Yang and Chen, 2008; Cheng et al., 2010; Deng, 2010; Yang, 2010; Wang and Chen, 2012; Editorial Office, 2013; Lu and Xu, 2014; Yang et al., 2014) for four major earthquakes. The data in Table 2 show that each emergency response improved relative to the previous ones. During this decade, the time of earthquake rapid reporting decreased from $19 \mathrm{~min}$ to $25 \mathrm{~s}$, and the time of the first press conference decreased from $26.5 \mathrm{~h}$ after an earthquake to $2 \mathrm{~h}$. Thus, disaster relief information could be released in a timely manner, helping to guide public opinion and thus maintain social stability in a disaster area. While emergency surveying and mapping improved from a technological perspective. The time of disaster assessment results release decreased from 109 to 4 days. The recovery of lifeline is faster with power recovery decreased from 105 to $2 \mathrm{~h}$, communication recovery decreased from 48 to $4 \mathrm{~h}$, traffic recovery decreased from 79 to $20 \mathrm{~h}$. The time of rescue teams' mobilization decreased from 30 to $5 \mathrm{~min}$ and deployed to the affected area as needs, due to constant exercise and improvement of national mechanism. Rescue forces are no longer excessively dispatched, 


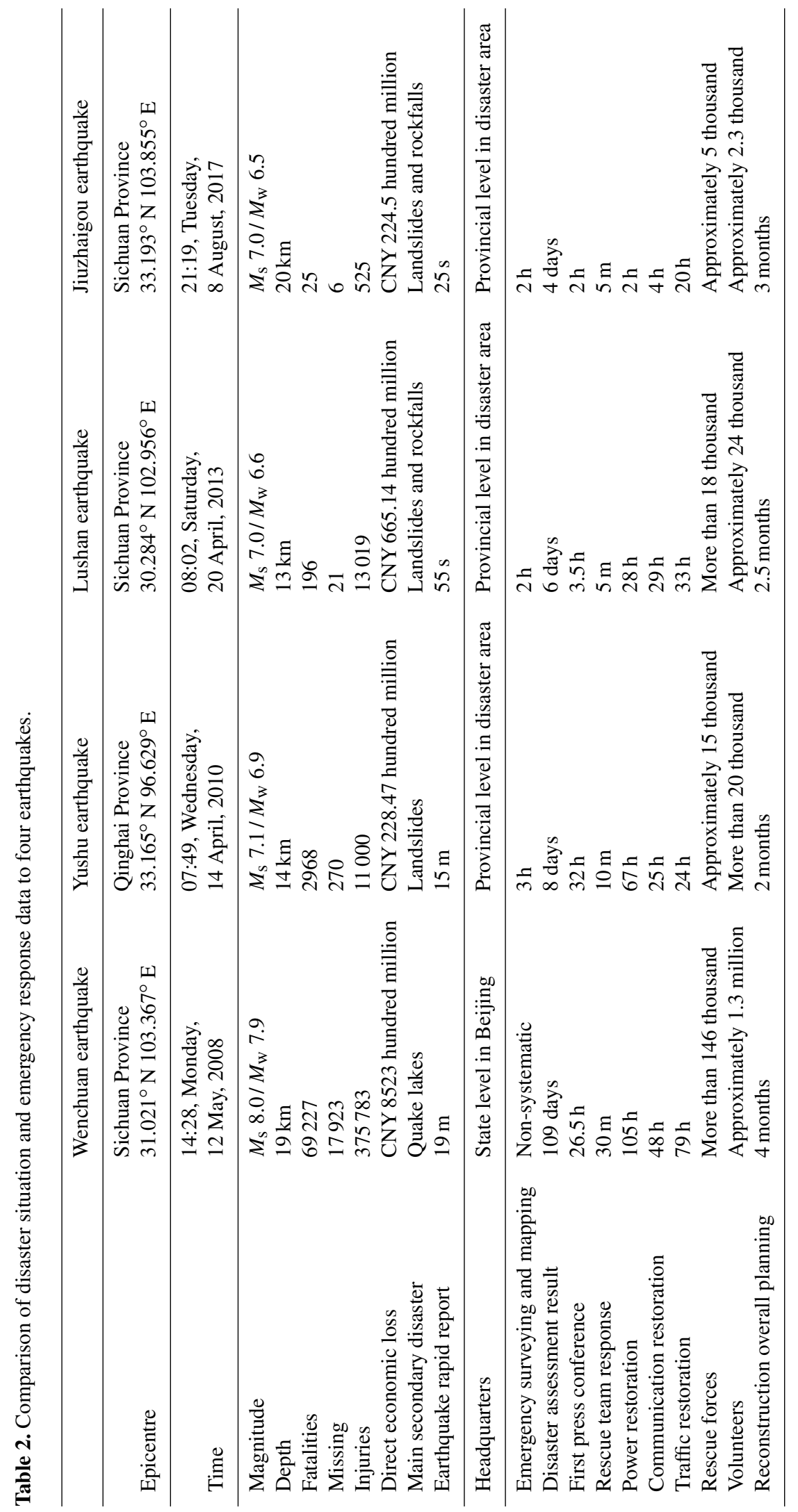


and a coordination mechanism for volunteers has been gradually established.

The major lessons learned from the Wenchuan earthquake were that having the State Council as the responsible body instilled a lack of initiative and mobility in local government and social forces. In addition, various rescue forces operated on their own without unified command and coordination, rescue resources were unevenly distributed and not all received professional search and rescue training, and there was no management of social organizations and volunteers. Following the Wenchuan earthquake, China revised the Law of the People's Republic of China on Protecting Against and Mitigating of Earthquake Disasters, strengthened the functions of all levels of government and enhanced departmental responsibilities, rescue capacity building and social participation.

The progress made during the Yushu earthquake was that the local government played a major role in the response and rescue operations. Thus, local resources were fully mobilized and rescue operations were relatively orderly. The major lessons learned from the Yushu earthquake including insufficient reserve of emergency supplies in remote areas as well as the lack of professional rescuers that could operate under special circumstances, because Yushu earthquake occurred on a plateau area with sea level above $3000 \mathrm{~m}$ (Wang, 2010). Afterwards, China revised the State Emergency Response Plan for Earthquake to specify that grade I and grade II emergency response operations in disaster area should be led by the provincial ECRH.

Sichuan Province is at the mercy of many natural phenomena and especially earthquake. The progress during the response to the Lushan earthquake was that the emergency response plan was immediately launched based on the response level, and regional forces and armed forces conducted a multi-sector joint rescue. The major lessons learned from the Lushan earthquake were that experience was still lacking in managing and coordinating social organizations and volunteers, resulting in serious road congestion. Thus, professional rescue forces could not access the area, and wounded victims could not be transferred.

In the Jiuzhaigou earthquake, the response activities of governmental departments at all levels were considered to be outstanding. The central governmental departments were able to efficiently activate their own emergency response plans and harness their respective strengths for rescue operations. Various departments were able to work in tandem to sensibly conduct multi-sector joint rescue efforts, i.e. without excessive dispatch of rescue forces. A command and coordination mechanism for disaster relief led by the local government and including a number of departments and social organizations was established immediately. This new structure was capable of efficiently mitigating problems with communication, electric power and traffic in the disaster area, and the airport and traffic access to the disaster area was controlled for the first time, thereby ensuring that disaster relief materials and rescue teams could access the disaster area in a timely manner.

\section{Analysis and summary}

The Jiuzhaigou earthquake exhibited three major characteristics. First, the number of casualties and collapsed buildings were lower than those during other earthquakes in China with similar magnitudes over the past few years. This is mainly because many buildings in the seismic region met seismic precautionary intensity requirements; their high anti-seismic properties led to lower rates of collapse and damage. Furthermore, the population density at the epicentre was relatively low. In addition, even though it was peak tourist season, the earthquake occurred in the evening, after most tourists had already departed from the scenic area or returned to their hotels. Second, the Jiuzhaigou scenic area, which is located in a 9-degree seismic region, is a Chinese State Natural Reserve and has been included in the World Natural Heritage List. The earthquake caused significant destruction of the natural landscape and environment. Third, the seismic area was located in a mountain gorge transition region prone to secondary disasters such as landslides and rockfalls. Over half of the 25 deaths that occurred during the earthquake were due to rockfalls or landslides. These events can easily block roads and are difficult to clear, which increases the danger and complicates disaster relief.

The provincial government of the disaster area immediately established a provincial ECRH to conduct the earthquake relief efforts. The SECRH launched a grade II emergency response and subsequently coordinated and organized departments and commissions under central leadership to conduct emergency rescue missions according to the needs of the disaster area. All levels of the government as well as ministries and commissions, enterprises and public institutions, search and rescue teams and social organizations launched their corresponding emergency response plans according to the disaster situation. Pursuant to their respective duties, each of these institutions displayed professional expertise while providing earthquake relief through close interdepartmental cooperation and multi-sector combined action. These entities accomplished many goals in a timely and skilful manner, including evacuating tourists, transferring and resettling the victims, caring for the wounded, performing search and rescue for the victims, collecting and distributing relief supplies, rapidly repairing the roads and restoring the electricity and communications. Furthermore, insurance companies immediately arranged for settlements of insurance claims. All of these efforts ensured social stability and orderly relief actions. After the $M_{\mathrm{S}}$ 8.0 Wenchuan earthquake of 2008, China revised the Law of the People's Republic of China on Protecting Against and Mitigating of Earthquake Disasters and the State Emergency Response Plan for Earthquake. These documents indicated that the local government should be 
responsible for the disaster response, and departments and commissions under central leadership should provide professional support. Based on lessons learned from the experiences of emergency response during the $M_{\mathrm{s}} 7.1$ Yushu earthquake in 2010 and the $M_{\mathrm{S}} 7.0$ Lushan earthquake in 2013, China's earthquake emergency response system has become more mature, and its response mechanisms have improved greatly.

The deployment of professional rescue forces and the response of social organizations were more rational than during previous earthquake emergency responses. Based on an assessment and evaluation of the disaster characteristics and development, only CISAR and professional rescue teams near the disaster area were mobilized following the earthquake. The Blue Sky Rescue Team deployed 259 rescuers to the front line, although it has more than 100000 volunteers at the national scale. Therefore, traffic jams did not occur from the over-deployment of rescue forces.

Based on the experiences of responding to the Wenchuan, Yushu and Lushan earthquakes, access to roads and airports in the disaster area was rapidly managed and controlled to ensure the timely arrival of relief materials and rescue teams. In addition, an effective command and coordination structure was established for social organizations to join the relief efforts. The Ministry of Civil Affairs provided an immediate bulletin and requested that social organizations and volunteers be subject to the overall management of the earthquake relief commanding agency in the disaster area (Ministry of Civil Affairs of the People's Republic of China, 2017). The local government of the disaster area constructed a work station especially to coordinate social organizations, registering arriving volunteers and providing them with jobs, controlling their numbers and limiting their ability to enter the disaster area based on the disaster situation and requirements. These endeavours, which helped organize resources as a whole, facilitated the sharing of information and engendered cooperation among the professional rescue teams and social organizations, making the rescue operations more orderly and effective. SECRH deployed a civilian helicopter rescue force that was advantageous in the special disaster environment to join rescue operations, thereby increasing the degree of cooperation between military and civilian organizations.

New techniques and technologies, including satellite remote sensing, UAV telemetry, big data and three-dimensional oblique photogrammetry for rapid disaster evaluations and landslide monitoring, played an important role in the earthquake emergency response and rescue missions. The mobile map service AMap opened a rescue lifeline that marked rescue routes for government sectors and social organizations and relief material handout stations. Earthquake thermodynamic maps are among the latest techniques that can provide data support for studying a disaster situation; these maps can be used to perform comprehensive and statistical analyses, determine the population size and characterize real-time changes in the disaster situation by using the push services of mainstream applications installed on smartphones.

The first people on the scene could never from professional rescue teams no matter how fast they response, thus selfrescue and mutual rescue by disaster victims are the effective measures for saving life and disaster reduction. Strengthen first responder training, whose missions include evacuation, rescue, crowd control and medical attention. Organize communities to carry out emergency response exercises. In addition to this, a specific emergency exercises at scenic areas with potential seismic risk in peak tourist season should be organized at regular intervals.

Data availability. Some of the rescue data are publicly available at http://www.xinhuanet.com/ (last access: 13 September 2017). The emergency response data of all ministries and commissions under the State Council are publicly available at their respective official websites. The remote sensing image data are provided by the remote sensing group at the Institute of Crustal Dynamics, China Earthquake Administration.

Author contributions. CH defined the scientific scope of the study. XA and QM collected the data, and WW wrote the paper. All authors discussed the results and commented on the paper.

Competing interests. The authors declare that they have no conflict of interest.

Acknowledgements. We thank the remote sensing group in the Institute of Crustal Dynamics, China Earthquake Administration, for providing the satellite remote sensing maps.

Edited by: Thomas Glade

Reviewed by: Peijun Shi and one anonymous referee

\section{References}

Alexander, D.: Principles of Emergency Planning and Management. Harpenden, UK and New York: Terra and Oxford University Press, 2002.

Alexander, D.: Disaster and Emergency Planning for Preparedness, Response, and Recovery, the Oxford Research Encyclopedia, Nat. Hazard Sci., 1-20, https://doi.org/10.1093/acrefore/9780199389407.013.12, 2015.

Bai, W.: "8.8" Jiuzhaigou Earthquake has Caused 25 People Dead and 525 People Injured, and the Work of Victims Search and Rescue has Basically End [EB/OL], available at: http://www.sc. gov.cn/10462/12771/2017/8/14/10430678.shtml, last access: 22 August 2017.

Chen, X. L., Yu, L., Wang, M. M., Lin, C. X., Liu, C. G., and Li, J. Y.: Brief Communication: Landslides triggered by the $M_{\mathrm{S}}=$ 
7.0 Lushan earthquake, China, Nat. Hazards Earth Syst. Sci., 14, 1257-1267, https://doi.org/10.5194/nhess-14-1257-2014, 2014.

Cheng, F., Dong, X., and Wang, S.: Emergency management of Yushu earthquake tests the Wenchuan experience, The J. Evid.Based Med., 10, 157-162, 2010.

China Earthquake Administration: the Emergency Response Plan for Earthquake of the China Earthquake Administration, 2013.

China Earthquake Administration: China Earthquake Administration Published the Seismic Intensity Map of Ms7.0 Jiuzhaigou Earthquake of Sichuan Province [EB/OL], available at: http://www.cea.gov.cn/publish/dizhenj/464/ 478/20170812211337414565961/index.html, last access: 13 September 2017.

China Meteorological Administration: the State Emergency Response Plan for Meteorological Disaster, 2010.

China Volunteer Service Federation: Pray for Earthquake Disaster Area, Volunteers Rescued Reasonably and With Love in Heart [EB/OL], available at: https://mp.weixin.qq.com/s?_biz=MzA4MjM2MDgzNAI T1 \textbackslash\%3D $\backslash \mathrm{T} 1 \backslash$ textbackslash\%3D\&idx $=1 \& \mathrm{mid}=$ 2650827698\&sn=38d759525a19c190cca19d0dc7e6a9c9, last access: 22 August 2017.

CISAR: National Earthquake Disaster Emergency and Rescue Team Carryout Rescue Operation on $M_{\mathrm{S}} 7.0$ Jiuzhaigou Earthquake of Sichuan Province [EB/OL], available at: http://www. toutiao.com/a6452652649400500750/, last access: 13 September 2017.

Coombs, W.: Ongoing Crisis Communication: Planning, Managing, and Responding, Sage Publications, Inc., 1999.

Deng, M.: Yushu earthquake disaster and emergency rescue, China emergency management, 55-58, 2010.

Department Of Civil Affairs Of Sichuan Province: Department of Civil Affairs has Allocated and Transported a Total of 3000 Cotton Quilts, 3000 Units of Cotton Clothes, 2000 Tents, 1000 Folding Beds, 3000 Sleeping Bags to Disaster Area Totally [EB/OL], available at: http://scmz.gov.cn/Article/Detail?id=21586, last access: 13 September 2017.

Editorial office: From 5.12 Wenchuan earthquake to 4.20 Lushan earthquake: review and think on the key link of reliek work in Lushan strong earthquake, China Emergency Management, 4, 13-21, 2013.

Gao, C.: Order is more Important than Passion in Earthquake Relief Work with Volunteers Constantly Emerging [EB/OL], available at: https://www.chinanews.com/sh/2017/08-15/8304864. shtml, last access: 13 September 2017.

General Office of the Aba Prefectural Government: the Emergency Response Plan for Earthquake of Aba Prefecture, 2012.

General Office of the Sichuan Provincial Government: the Emergency Response Plan for Earthquake of Sichuan Province, 2012.

General Office of the State Council: the General State Emergency Response Plan for Unexpected Public Emergencies, 2006a.

General Office of the State Council: the State Emergency Response Plan for Paroxysmal Geologic Hazards, 2006b.

General Office of the State Council: the State Emergency Response Plan for Earthquake, 2012.

General Office of the State Council: the State Emergency Response Plan for Natural Disasters' Relief, 2016.

Greiving, S., Pratzler-Wanczura, S., Sapountzaki, K., Ferri, F., Grifoni, P., Firus, K., and Xanthopoulos, G.: Linking the ac- tors and policies throughout the disaster management cycle by "Agreement on Objectives" - a new output-oriented management approach, Nat. Hazards Earth Syst. Sci., 12, 1085-1107, https://doi.org/10.5194/nhess-12-1085-2012, 2012.

Li, Z., Chen, X., Teng, H., and Xiu, Z.: Infectious Kinetics of SARS Epidemic, Prog. Biochem. Biophys., 31, 167-171, 2004.

Liu, Z. and Li, Y.: Analyze on Chinese earthquake emergency response mechanism by Yushu earthquake, China Emerg. Res., 5, 18-21, https://doi.org/10.19384/j.cnki.cn115524/p.2010.05.006, 2010.

Lu, Y. and Xu, J.: The progress of emergency response and rescue in China: a comparative analysis of Wenchuan and Lushan earthquakes, Nat. Hazards, 74, 421-444, https://doi.org/10.1007/s11069-014-1191-7, 2014.

Ministry of Civil Affairs of the People's Republic of China: The No. 411 Announcement from Ministry of Civil Affairs about Social Forces Participate in Earthquake Relief Work Orderly of $M_{\mathrm{S}} 7.0$ Jiuzhaigou Earthquake of Sichuan Province, 2017.

Ministry of Transport of the People's Republic of China: the Emergency Response Plan for Highway Traffic, 2009.

Perry, R. and Lindell, M.: Preparedness for emergency response: Guidelines for the emergency planning process, Disasters, 27, 336-350, https://doi.org/10.1111/j.0361-3666.2003.00237.x, 2003.

Qian, F.: People's Armed Police Invested Nearly Two Thousand Soldiers in Jiuzhaigou Earthquake Emergency Rescue [EB/OL], available at: https://news.youth.cn/jsxw/201708/ t20170810_10481852.htm, last access: 13 September 2017.

Standing Committee of the National People's Congress: the Law of the People's Republic of China on Protecting Against and Mitigating of Earthquake Disasters, 2008.

The 10th Standing Committee of the National People's Congress: the Emergency Response Law of the People's Republic of China, 2007.

Wang, S.: Revelation on emergency rescue of "4.14" Yushu earthquake by field research on disaster area of Yushu earthquake, Tibet Development Forum, 4, 47-49, 2010.

Wang, L.: Thirty enterprises participated in emergency rescue in 12 hours after Jiuzhaigou earthquake of Sichuan Province [EB/OL], available at: http://www.jianzai.gov.cn//DRpublish/ ztzl/0000000000025485.html, last access: 22 August 2017.

Wang, Y.: They never stopped rescuing in 36 hours after Jiuzhaigou earthquake [EB/OL], available at: http://news.xinhuanet.com/ politics/2017-08/10/c_129677481.htm, last access: 13 September 2017 .

Wang, Y. and Chen, H.: The effect of earthquake pre-plan to earthquake emergency response in China - Taking Tangshan and Wenchuan earthquakes as examples, Recent Developments in World Seismology, 11, 17-22, https://doi.org/10.3969/j.issn.0235-4975.2012.11.008, 2012.

Wu, W., Wang, X., and Deng, F.: Compilation and spatial analysis of co-seismic landslide inventory by using high-resolution remote sensing images in earthquake emergency response an example of the Jiuzhaigou $M_{\mathrm{S}} 7.0$ earthquake on August 8, 2017, Technol. Earthq. Disaster Prev., 12, 815-825, https://doi.org/10.11899/zzfy20170410, 2017.

Yang, C. and Chen, W.: Volunteers' Roles after Whenchuan Earthquake, J. Inst. Disaster-Prev. Sci. Technol., 10, 138-140, 2008. 
Yang, M.: The beauty of the heart - approach Yushu volunteers, Soc. Pub. Benefit, 1, 76-82, 2010.

Yang, J., Chen, J., Liu, H., and Zheng, J.: Comparison of two large earthquakes in China: the 2008 Sichuan Wenchuan Earthquake and the 2013 Sichuan Lushan Earthquake, Nat. Hazards, 73, 1127-1136, https://doi.org/10.1007/s11069-014-1121-8, 2014.

Zheng, T. and Zheng, Y.: Review of earthquake disaster loss in Chinese mainland in 2013, J. Nat. Disas., 24, 239-246, https://doi.org/10.13577 /j.jnd.2015.0130, 2015.
Zheng, T., Li, Y., Hou, J., and Mi, H.: Review on earthquake disaster loss in Chinese mainland in 2008, J. Catastrophol., 25, 112-118, 2010.

Zheng, T., Zhao, P., and Liu, Z.: A review of earthquake disaster loss in Chinese mainland in 2010, J. Nat. disasters, 20, 107-113, 2011. 